DOS S I Ê FOU CAULT 


\title{
O CUIDADO DE SI NA GRÉCIA ANTIGA: ELEMENTOS PARA UMA DISCUSSÃO COM OS DOIS PRIMEIROS CURSOS DA HERMENÊUTICA DO SUJEITO, DE MICHEL FOUCAULT ${ }^{1}$
}

\author{
Antonio Orlando Dourado-Lopes $\star$ \\ Universidade Federal de Minas Gerais
}

\begin{abstract}
Foucault's interpretation of the Socratic conception of knowledge in his Herméneutique du sujet neglects the importance of the daimónion to the meaning of the delphic maxim "know thyself". I propose an overview of the archaic Greek notion of divine intervention as a contribution to the debate proposed by Foucault in his last seminars in the Collège de France.
\end{abstract}

KEYWORDS: Foucault; Socrates; taking care of oneself; daimon .

\begin{abstract}
os dois primeiros cursos da Hermenêutica do sujeito, de 6 e 13 de janeiro de 1982, Foucault introduziu a temática do "cuidado de si" a partir de uma rápida contraposição à apropriação socrática da máxima délfica "conhece-te a ti mesmo". O final do segundo curso resume essa abordagem do seguinte modo:

\footnotetext{
^ aoodlopes@gmail.com

${ }^{1}$ Texto originalmente apresentado no "II Congresso Nacional de Psicanálise, Direito e Literatura", do Centro de Extensão da Faculdade de Direito Milton Campos, em Belo Horizonte, de 26 a 30 de abril de 2010. Numa versão reduzida, o mesmo texto foi apresentado nas "Jornadas Michel Foucault", do "Núcleo de Estudos Antigos e Medievais", NEAM/ FALE-FAFICH/ UFMG, em 9 e 10 de setembro de 2010, Belo Horizonte - MG. Agradeço aos organizadores de ambos os eventos pela oportunidade: Fábio Belo, Guaracy Araújo e Gustavo Cerqueira Guimarães, no primeiro caso, e Tereza Virgínia Ribeiro Barbosa, no segundo.
} 
Com efeito, parece-me que o que vai caracterizar o cuidado de si na tradição platônica e neoplatônica é, de um lado, que o cuidado de si encontra sua forma e sua realização no conhecimento de si como forma, senão única, ao menos absolutamente soberana do cuidado de si. Em segundo lugar, será igualmente característico da corrente platônica e neoplatônica o fato de que esse conhecimento de si, como expressão maior e soberana do cuidado de si, dá acesso à verdade e à verdade em geral. Enfim, em terceiro lugar, será característico da forma platônica e neoplatônica do cuidado de si o fato de que o acesso à verdade permite, ao mesmo tempo, reconhecer o que pode haver de divino em si. Conhecer-se, conhecer o divino, reconhecer o divino em si mesmo: isso é, eu creio, fundamental na forma platônica e neoplatônica do cuidado de si. Esses elementos, nós não os acharemos - em todo caso, não distribuídos e organizados assim nas outras formas [do cuidado de si], epicurista, estoica ou mesmo pitagórica, apesar de todas as interferências que pode ter havido entre os movimentos neopitagóricos e neoplatônicos dali em diante. ${ }^{2}$

A referência ao platonismo (e não aos diálogos de Platão), bem como sua vinculação ao neoplatonismo sem maiores ressalvas já deveria acautelar-nos quanto à amplitude do contexto examinado por Foucault. Trata-se de uma abordagem genérica, que atende aos propósitos da ampla pesquisa temática anunciada, mas fica inevitavelmente sujeita a imprecisões na recuperação dos usos mais antigos das expressões examinadas.

Com o intuito de enriquecer essa abordagem e sem, por outro lado, desmerecer em nada os belos frutos da longa investigação de Foucault, apontarei a seguir uma distorção particularmente grave na exposição feita nesses dois primeiros dias do curso do filósofo francês, a saber: a atribuição de um sentido excessivamente restritivo à noção de "conhecimento" na sua interpretação do imperativo aoristo gnôthi, "conhece", nas referências platônicas à máxima délfica. A valorização da fortuna clássica e helenística do princípio do "cuidado de si" acabou por permitir que se introduzisse subrepticiamente nas análises de Foucault uma compreensão positiva de conhecimento cultivada por autores posteriores mas totalmente estranha ao ambiente das discussões socráticas.

${ }^{2}$ Cf. Foucault, M. Herméneutique du sujet. Cours au Collège de France 1981-1982. Édition établie, sous la direction de F. Ewald et A. Fontana, par F. Gros. Collection "Les Hautes Études". Paris: Gallimard/Seuil, 2001 (aulas de 6 e de 13 de janeiro de 1982, p. 75). As traduções aqui apresentadas, salvo menção contrária, são de minha responsabilidade. 
Em oposição à valorização da fortuna do "conhece-te a ti mesmo" mas, ainda assim, preservando a perspectiva de longo prazo, pareceme útil remeter os diálogos platônicos ao debate que eles próprios propuseram com a tradição poética grega e na qual, por força do mesmo, se inseriram. Ressaltarei as afinidades das posturas platônicas com as de poetas e pensadores que o antecederam, particularmente no que tange ao caráter divino do conhecimento.

\section{Três dimensões do cuidado na poesia arcaica}

A primeira observação sobre a noção grega de "cuidado" é a de que ela aparece na literatura grega estreitamente associada ao conhecimento, representada em histórias e por personagens que encenam as peripécias e as virtudes de se estar de posse ou a caminho da posse de algum tipo de informação vital. $\mathrm{Na}$ Odisseia, essa relação entre o cuidado e o conhecimento é salientada no herói ímpar que protagoniza o poema, um expoente da inteligência mais aguda e mais ampla, operada pelo nóos, versado também na inteligência prática das phrénes. Essa espécie de dualidade da sua inteligência viabiliza suas ações nas conjunturas mais desfavoráveis em que o lança um destino implacável. Omitindo cuidadosamente seu nome, o início do poema o apresenta como aquele que: ${ }^{3}$

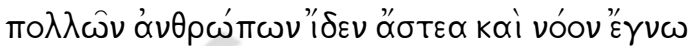

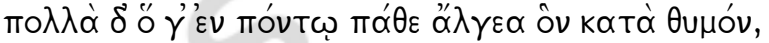

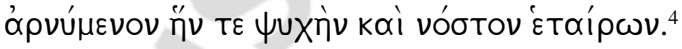

O cuidado de Odisseu é aqui indicado tanto pelo conhecimento dos homens em geral que adquiriu (v. 3) quanto por seu esforço em preservar a vida dos companheiros (v. 5). Na figura desse herói, a sabedoria é fruto de uma inteligência que se dirige aos homens, que dedica-se a conhecê-los para melhor ter com eles, e que se desdobra no apego aos mais próximos. Vemos esse sentimento de afinidade com

\footnotetext{
${ }^{3}$ A importância da omissão do nome de Odisseu nessas primeiras linhas do poema foi salientada com muita propriedade por Clay, J. S. The wrath of Athena. Gods and men in the "Odyssey". Lanham/Boulder/New York/ London: Rowman \& Littlefield, 1997, p. 26-29.

${ }^{4}$ Odisseia I, 3-5: "De muitos seres humanos viu cidades e conheceu a inteligência,/ no mar muitas dores penou em seu ânimo/ empenhando-se por sua vida e o retorno dos companheiros".
} 
os companheiros exemplificado em diversos episódios. É por aventurarse a encontrar homens desconhecidos, por fazer dessa procura um guia para seus rumos, que Odisseu é, entre todos, o grande herói épico da sabedoria. Não há, parece-me, episódio mais revelador do que sua opção por escutar as sereias amarrado ao mastro do navio, um dos dois procedimentos recomendados por Circe. ${ }^{5}$

Além de mostrar o cuidado como fruto da inteligência, a Odisseia destaca uma segunda característica que terá também longa fortuna na poesia grega: o de gerar preocupação. Ao se dirigir a um objeto de afeição e depender de um futuro incerto, o cuidado gera um sofrimento antecipado e, nesse sentido, um dano por antecipação causado pela aflição com a eventual perda. Nesses casos, emprega-se o verbo kédomai, "cuido de", "preocupo-me com", que se deriva de kédo, "inquieto-me", "aflijome". ${ }^{6}$ O protagonista da Odisseia zela por seus companheiros mas é também objeto do cuidado afetuoso da deusa Atena e de alguns dos seus servidores em Ítaca, paradigmas de devoção e lealdade. ${ }^{7}$ Por isso, o termo kédos aparece em alguns dos diálogos mais importantes do poema. Lembremo-nos de quando Atena se revela a Odisseu, recémchegado a Ítaca, que se mostra incapaz de reconhecer a deusa, disfarçada num jovem caminhante. Repreendendo-o docemente por não reconhecê-la, Atena evoca o cuidado que lhe dedicara desde a passagem pela terra dos feácios:

\footnotetext{
${ }^{5}$ Cf. Segal, C. Celui qui a tout vu. Europe. Paris, vol. QCCCLXV, p. 68-101, 2001; em particular p. 70-71, que marca a diferença entre o herói mitológico de Fertilidade e o de Sabedoria, sendo Odisseu do segundo tipo; ver também o seguinte comentário sobre a vékuı (p. 96-97): "O conhecimento particular que o herói traz de seu contacto com a morte permite à aventura da vida continuar. É a maneira que tem o poeta épico de estabelecer um equilíbrio, indispensável à existência, entre a realidade e a esperança". Sobre a importância do conhecimento e da curiosidade em geral como características de Odisseu, cf. também Rutherford, R. B. The philosophy of the "Odyssey". In: de Jong, I. J. F. (Org.). Homer. Critical assessments. Vol. IV: Homer's art. London/New York, Routledge, 1999, p. 271-298.

${ }^{6}$ Odisseia XI, 542; Trabalhos e os dias, 49 (Zeus trouxe aflições aos homens privando-

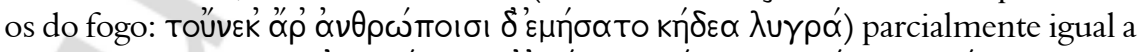

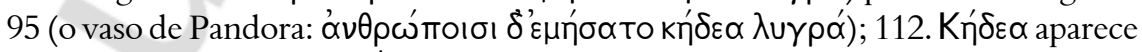

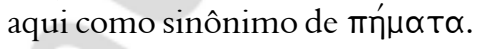

${ }^{7} \mathrm{O}$ zelo de Atena por Odisseu na Odisseia pode ser mais um elemento dos diversos em que se percebe uma tentativa do poeta de equipará-lo com Héracles (cf. Kullmann, W. Das Wirken der Götter. Untersuchungen zur Frage der Entstehung des homerischen “Götterapparatts". Berlin: Akademie, 1956, p. 33-35).
} 
Miserável, ardiloso, insaciável em dolos, não deixarias, mesmo em tua própria terra, de exercitar tuas trapaças e o discursos sorrateiros que do fundo te são tão caros! Mas não falemos mais essas coisas, sabendo ambos artimanhas, já que de longe és o melhor dos mortais todos no conselho e nas palavras, e eu entre os deuses todos sou apontada pela astúcia e as artimanhas. Não reconheceste Palas Atena, jovem de Zeus, que sempre a ti, em todas as penas, amparo e protejo, te fiz querido aos feácios todos e agora de volta aqui chego, para contigo urdir astúcia e as riquezas esconder tantas, que os magníficos feácios te concederam no retorno, por meu plano e inteligência. Dir-te-ei quantas aflições em teu palácio bem feito cabe suportares: hás de aguentar por força e nada de te declarares a homens ou mulheres, qualquer que seja, pois vieste depois de errares! Quieto sofre as muitas dores e os golpes dos homens aguenta! ${ }^{8}$

A solicitude do porqueiro Eumeu é destacada pela deusa quando propõe o plano de ação de Odisseu em Ítaca. Além de cuidar diligentemente dos porcos, Eumeu tem Odisseu em alta estima. ${ }^{9}$

Essas referências ao cuidado na Odisseia valorizam-se pelas narrativas dos diversos perigos que permeiam o poema. Quanto mais incerto o futuro do ser a que se dirige o cuidado, mais este se justifica e mais se realiza como preparação do futuro. É por essa associação de ideias que entram em cena as noções de meléte, "cuidado com acontecimentos vindouros", e de paraskeué, "preparação de uma empresa".

${ }^{8}$ Odisseia XIII, 293-310.

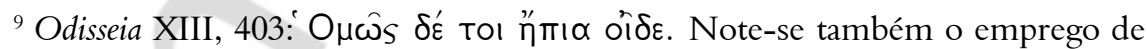

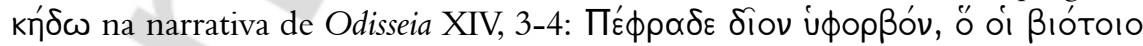
$\mu$ á̉ Eumeu pede a Odisseu que conte de onde vem e todas as aflições que suportou:' Eı пฺ̣S óm

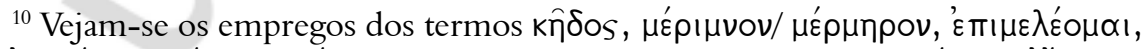

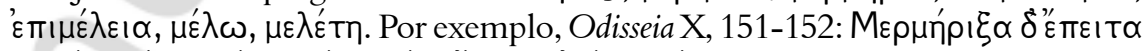

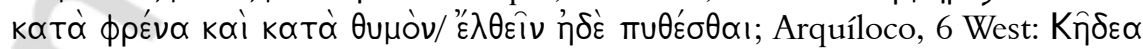

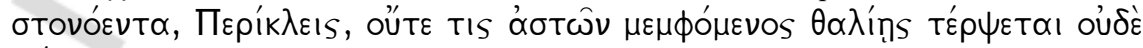
mó$\lambda$ Is. Cf. as observações de Foucault sobre essa terminologia, salientando que todos os termos remetem a algum tipo de atividade (cf. Foucault, op. cit., 2001, p. 82-84). 
É significativo que uma tradição poética, infelizmente transmitida muito precariamente, fez de Melété o nome de uma das três Musas, ao lado de Mnémę, "Memória", e Aoidé, "Canto": além de nos permitir lembrar os grandes feitos do passado e de nos encantar com a beleza do canto, as Musas nos possibilitariam cuidar daqueles para quem cantamos e dos que não deixamos serem esquecidos no curso do tempo. ${ }^{11}$ Por ser um dom dos deuses, "cuidar" é divino; por dirigir-se àqueles por quem nos afeiçoamos, é a mais humana das ocupações. ${ }^{12}$

\footnotetext{
${ }^{11}$ Como nos lembra Detienne, M. Les maîtres de vérité dans la Grèce archaïque. Paris: Pocket, 1985, p. 52-53. Essa tradição é transmitida por Pausânias IX, 29, 2-3 e corresponde a um culto às Musas localizado no monte Hélicon. Detienne concorda com B. A. van Groningen (Les trois Muses de l'Hélicon. L'Antiquité Classique. Louvain, p. 287-296, 1948) quanto à antiguidade desse culto, que remontaria a uma época anterior a Aristóteles, e nos lembra ainda da tradição transmitida por Cícero, De natura deorum III, 54, para a qual as Musas seriam quatro: 'ApXń, $M_{\varepsilon} \lambda \varepsilon^{\prime} T \eta$, , Aoı $\delta$ '́, $\Theta \varepsilon \lambda \xi ı$ เvoń. Parece-me, entretanto, que a interpretação de Detienne para o sentido de $M \varepsilon \lambda \varepsilon \dot{t}$ Tn nesse contexto é um tanto apressada, limitando-o a "disciplina indispensável ao aprendizado do ofício do aedo" e deixando de lado o sentido de "solicitude", igualmente importante e amplamente atestado para o emprego do termo na época clássica. A interpretação de Detienne considera o nome das Musas em relação à preparação do aedo, ao passo que o nome de pelo menos mais uma delas, $\Theta \varepsilon \lambda \xi ı$ ıvon - derivado de $\theta \dot{\varepsilon} \lambda \gamma \omega$ ("enfeitiçar", "encantar") - indica claramente o efeito do canto sobre os ouvintes. Por esse ângulo, os respectivos nomes indicariam as diferentes dimensões do nosso estado ao sermos envolvidos pelo canto, podendó Apxń ser a confiança que então nos investe na realização dos nossos desejos e’ Aoı $\delta$ a a veracidade única a que acedemos pelo que aprendemos a partir do conhecimento divino das deusas. Embora pertencente a uma tradição diferente a respeito dos nomes individuais e do número das Musas, talvez possamos interpretar $M_{\varepsilon} \lambda \varepsilon \dot{\varepsilon}$ Tn evocando ainda a passagem em que Hesíodo afirma que, ao ouvir o canto, aquele cujo coração é acometido por recente aflição

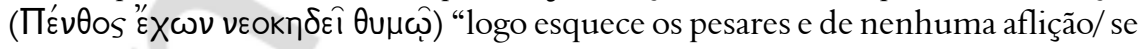
lembra, já os desviaram os dons das deusas" (Teogonia, 98-103; 102-103 para a citação:

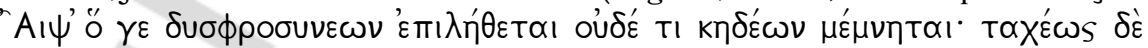

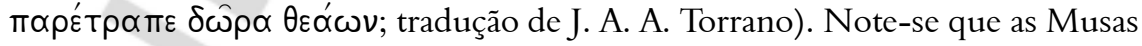
não abolem as nossas dificuldades, apenas cuidam de nós fazendo-nos esquecer das aflições geradas pelo cuidado que temos por aqueles a quem nos afeiçoamos. A atenção que recebemos das deusas nos alivia do sofrimento excessivo nascido desse cuidado, mas não o descaracteriza como condição par excellence da dignidade humana. ${ }^{12}$ No sentido da distinção mitológica tradicional entre animais, homens e deuses, pois estes podem cuidar de nós quando querem, mas sua relação com os mortais costuma ser caracterizada na literatura grega por um desprezo generalizado.
} 
A valorização do cuidado na sua atribuição ao divino e ao que é o melhor nos homens nos remete ainda a uma terceira dimensão na literatura grega arcaica, qual seja, aquela em que aparece como sentimento de nobreza. É o que se verifica nos usos do adjetivo kednós, derivado de kédo, "ocupar-se com", e significando, no sentido ativo, "sensato", "prudente", "fiel", "devotado", e no sentido passivo, "querido", "estimado", "digno de consideração". O ato de cuidar enobrece porque supõe, de um lado, um distanciamento a respeito das funções imediatas do trabalho do homem comum e, de outro, o poder de interceder por aquele por quem zelamos. Seja como experiência ativa, seja como passiva, o cuidado distingue aqueles a quem toca. ${ }^{13}$

Inteligência, preocupação e nobreza são, então, os diferentes aspectos do cuidado que a tradição poética grega cultivou desde seus testemunhos mais antigos, nos poemas homéricos, até as recomendações socráticas dos diálogos platônicos. Quando Foucault a recupera a partir do Alcibíades, a temática já era muito mais ampla e rica do que ele parece perceber, atribuindo de um modo um tanto vago ao que chama de "corrente platônica e neoplatônica" elementos que já estruturavam a cultura grega unindo mitologia, religião e literatura. ${ }^{14} \mathrm{~A}$ vinculação à máxima délfica, pleiteada por Platão na Apologia de Sócrates e no (questionavelmente autêntico) Alcibiades, apenas mantém-se fiel à combinação do divino com o humano característica da religião grega. A mesma combinação encontra-se nos poemas homéricos, nos de Hesíodo e em tantos belos momentos da poesia grega com a qual Platão dialoga incessantemente ao longo de toda a sua obra.

\section{As vicissitudes do daímon e a firmeza do saber}

As características e a importância do cuidado nas relações humanas, tais como apresentadas já a partir dos poemas homéricos, correspondem a uma concepção da experiência elaborada no contexto de crenças religiosas antropomórficas. Essas caracterizam-se por grande ênfase no paralelismo entre deuses e homens, tornando difusa a fronteira entre ambos. ${ }^{15}$ Por sua vez, ao mesmo tempo em que a proximidade dos deuses sugere o conforto de uma eventual proteção, é também dela que nasce a compreensão

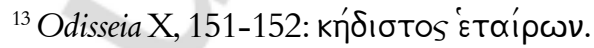

${ }^{14}$ Cf. Foucault, op. cit., 2001, p. 1-77.

${ }^{15}$ Para as principais referências teóricas a esse tema, cf. Dourado-Lopes, A. O. A força e o antropomorfismo dos deuses gregos. Considerações sobre a religião dos poemas homéricos. Aletria. Revista de Estudos de Literatura. Belo Horizonte, v. 19, n. 3, p. 11-27, julho-dezembro de 2009.
} 
da sujeição da existência mortal à influência imprevisível de um daímon, isto é, de uma divindade desconhecida agindo por motivações obscuras. Muitas vezes essa influência é negativa, inclusive porque, no contexto dos poemas homéricos, a imprevisibilidade é em si uma experiência negativa. ${ }^{16}$ Esse lado negativo da proximidade do divino é determinante para a noção grega de cuidado: o cuidado dos homens pelos deuses logo pode tornar-se o cuidado dos homens apesar dos deuses.

Em meio às muitas discussões ainda vivas sobre o sentido de daímon, não sabemos, no final das contas, o que significaria propriamente esse termo nem por que existe lado a lado com theós, seu sinônimo parcial. Entre os diversos empregos, salientemos aqueles em que a vitória num combate ainda em curso é atribuída a um daímon; em que um herói enfurecido e com confiança descabida - prestes a morrer derrotado - é comparado a um daímon; em que um acontecimento infeliz é atribuído a um daimon.$^{17}$ Para citar um exemplo eloquente, quando o rei Éolo vê Odisseu de novo em seu palácio, após ter usado seus poderes especiais para enviá-lo com ventos propícios de volta a Ítaca, pergunta-lhe indignado: "Como vieste, Odisseu? Que divindade maligna te acometeu?"18 Em sua indignação, Éolo acaba expulsando o herói de sua ilha, pois não lhe "é justo ocupar-se ou enviar/ um homem odiado pelos deuses bemaventurados". ${ }^{19}$ Note-se, assim, que a atribuição do infortúnio de Odisseu a uma "divindade maligna" (kakòs daímonn) não impediu Éolo de ter certeza de que o herói era odiado pelos "deuses bem-aventurados".

\footnotetext{
${ }^{16}$ Os deuses homéricos só utilizam seu poder de manipular a realidade mortal negativamente, para afastar os heróis de uma situação de perigo, jamais para colocálos em alguma parte com vistas a realizar uma ação prevista. Os deuses "corrigem" ou "retardam" a ação heroica. Eles podem, por exemplo, evitar que ela seja excessiva, desmedida, rápida ou brutal demais, mas jamais a produzem.

${ }^{17}$ Os deuses em geral: Ilíada I, 222; VII, 248; Odisseia XII, 169; XIV, 386; XV, 261; XVI, 370; XVII, 243; XVIII, 146; XIX, 138 e 512; XXI, 201; vitória num combate: Ilíada VII, 291-292, 377-378 e 396-398; um herói enfurecido é comparado a um

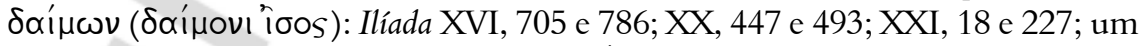
acontecimento infeliz é atribuído a um $\delta \alpha i ́ \mu \omega v$ : Ilíada XV, 468; XXI, 93; Odisseia III, 166; IV, 275; V, 396 e 421; VI, 172; XI, 61 e 587; XII, 295; XIV, 488; XVI, 64 e 194; XVII, 446; XVIII, 256; XIX, 129; XIX, 201; XX, 87; XXIV, 149 e 306 (cf. Shipp, G. P. Studies in the language of Homer. Cambridge: University Press, 1972, p. 193).

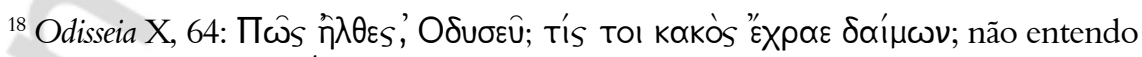
que aqui o adjetivo Kokós acrescente uma informação, parece-me antes apenas explicitar

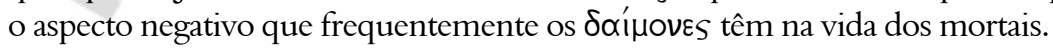

${ }^{19}$ Odisseia X, 72-75.
} 
Algumas vezes o daímon é mencionado por um herói como responsável por sentimentos ou pensamentos favoráveis ou nocivos. Exemplo de um pensamento nocivo enviado a um herói aparece no que diz Fênix a Aquiles, no episódio da Ilíada conhecido como "embaixada". Depois de contar-lhe a história de Meleagro, o ancião recomenda a Aquiles que não siga esse mau exemplo:

Mas tu não me venhas a pensar assim; que uma divindade não te vire para lá, meu caro; seria pior defender as naus incendiadas $(\ldots.) .^{20}$

Nosso estranhamento diante da noção de daímon corresponde, ao menos em parte, à dificuldade em compreender a concepção homérica da ação divina, como notou Nilsson:

O homem homérico está submetido ao domínio do instante (Der homerische Mensch ist der Herrschaft des Augenblicks unterworfen); quando o êxtase desapareceu, quando as consequências incuráveis se instalam, ele se dá conta sinceramente de que não as quis, e de que também não as produziu; porque seu próprio comportamento se tornou estranho a ele próprio e ele não o compreende; aparece-lhe agora como algo estranho, que se imiscuiu do exterior. Isso não pode advir de um deus protetor, mas somente de uma força estranha e mesmo hostil. $\mathrm{O}$ homem chama essa força de daímon ou de theós (tis), de theoí e também de Zeús, designações que se encobrem parcialmente e são intercambiáveis. (...) Para se falar em provas, são tão numerosas as passagens em que um daimon conduz um homem a algum lugar contra a sua vontade ou a sua intenção ou expectativa, como Odisseu à Esquéria, à ilha de Calipso e de volta a Éolo, (...). Em não menos passagens um daímon insere repentinamente um pensamento em um homem, (...). Para resumir, o daímon produz o inesperado, o inesperado no homem; ele deve assumir tudo o que o homem não pode esclarecer. (...) daímon é anônimo, sem definição de gênero, e carece de certos atributos (...) não tem nenhuma individualidade precisa, mas deve sua individualidade ao acontecimento em que se manifesta, ele é apenas uma impressão da crença de que uma força superior produziu o acontecimento. ${ }^{21}$

\footnotetext{
${ }^{20}$ Ilíada IX, 600-602.

${ }^{21}$ Cf. Nilsson, M. P. Geschichte der griechischen Religion. I. Band: die Religion Griechenlands bis auf die griechische Weltherrschaft. Munique: C. H. Beck'sche, 1967, p. 361-374; p. 219-220 para a citação; Lesky, A. Göttliche und menschliche Motivation im homerischen Epos. Sitzungsbericht der Heidelberger Akademie der Wissenschaften.
} 
Na mesma direção vão as observações de Burkert:

Daímones não indica uma classe precisa de essências divinas, mas uma efetividade singular (eine eigentümliche Wirkungsweise). Porque daímon e theós também não são facilmente intercambiáveis. (...) Cada deus pode agir como um daímon; não há deus a se descobrir em cada agir. Daímon é a face escondida do agir divino. Não há nenhuma imagem de um daímon , não há nenhum culto. ${ }^{22}$

Deixemos de lado os poemas homéricos e caminhemos na direção de Platão. A noção de "cuidado" assume nova importância na época arcaica por causa do sentimento de fragilidade e de vulnerabilidade da condição humana que então se acentua. Prevalece na literatura grega uma "consciência profunda da insegurança e do desespero humanos (amekhanía), que tem seu correlato religioso no sentimento da hostilidade divina". ${ }^{23}$ Não se trata de uma crença diferente, mas de uma reação emocional diferente ao mesmo olhar sombrio para a realidade humana que já se conhecia.

Os autores da época arcaica reportam-se frequentemente à inveja dos deuses, uma hostilidade poderosa e imprevisível que pode atingir

Heidelberg: Heidelberger Akademie der Wissenschaften, 1961, p. 5-52; em particular p. 23-24. Cf. também Daraki, M. Le héros à "menos" et le héros "Daimoni Isos". Une polarité homérique. Annali della Scuola Normale Superiore di Pisa. Pisa, vol.X, p. 1-24, 1980; em particular p. 2-3, que aborda os problemas concernentes à tradução de daimon, normalmente "deus" ou "ser maligno".

${ }^{22}$ Cf. Burkert, W. Griechische Religion der archaischen und klassischen Epoche. Die Religionen der Menschheit, 15. Stuttgart/Berlin/Köln/Mainz: W. Kohlhammer, 1977, p. 278-282 e 408; p. 279-280 para a citação. Nilsson, M. P. Geschichte der griechischen Religion. I. Band: die Religion Griechenlands bis auf die griechische Weltherrschaft, p. 216-

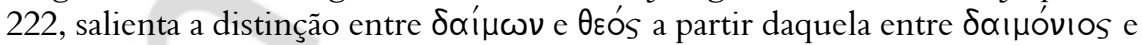

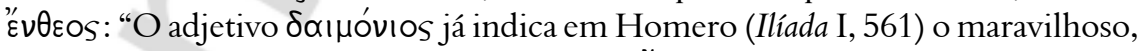
o incompreensível, enquanto com a palavra " tipo de aspiração divina" (p. 218).

${ }^{23}$ Cf. Dodds, E. R. The Greeks and the irrational. Berkeley/ Los Angeles/ London: University of California Press, 1951, p. 29-31; Clay, op. cit., p. 229, observa que a Odisseia afirma a instabilidade do destino para valorizar a resistência do homem que o suporta. A influência do poema certamente contribuiu para a visão de mundo da época arcaica (cf. o que diz Odisseu a Anfínomo, um dos pretendentes, censurando-o pela maneira desrespeitosa com que vinha se comportando: Odisseia XVIII, 123-149). 
todo mortal que se projete acima dos demais. ${ }^{24}$ Para Hesíodo, o movimento de deterioração da humanidade é inevitável, como se toda mudança não pudesse senão levar ao pior. ${ }^{25}$ A noção hesiódica de éris, "disputa", bem como a noção heraclítica de pólemos, "guerra", traduzem o olhar desencantado para um mundo em que a oposição entre indivíduos é o que existe de mais constante. ${ }^{26}$

Dizia no começo dessa exposição que desde os poemas homéricos o cuidado é uma forma de conhecimento, ou seja, é motivado pela afeição e, na medida em que visa à salvaguarda e ao bem-estar do seu objeto de afeto, desdobra-se na ação que levará a tanto. Cuidar é, portanto, agir motivado por um afeto. Acrescentemos a esse breve inventário das relações entre conhecimento, cuidado e afeto o dado de que desde muito cedo na literatura grega o conhecimento é valorizado por ser estável. A estabilidade é uma característica da inteligência confiável, que nos orienta para os nossos desejos: é desejável que a inteligência seja estável para poder ser um guia confiável. ${ }^{27}$ Essa característica é salientada pelo uso frequente do adjetivo émpedos, "firme", "aprumado", quando se afirma, por exemplo, que "continuava firme a inteligência" de Pátroclo, logo após ser ferido por uma flecha em sua coxa, assim como a inteligência dos companheiros de Odisseu, transformados em porcos por Circe e, excepcionalmente, a inteligência da sombra de

\footnotetext{
${ }^{24}$ Dodds, op. cit., p. 30-31, em particular: "A moralização do $\phi \theta$ óvos introduz-nos num segundo traço característico do pensamento arcaico religioso - a tendência para transformar o sobrenatural, em geral, e Zeus, em particular, num agente de justiça”. À p. 29, o autor remete às passagens de Heródoto (I 32; III 40; VII 10) que dizem que a divindade é $\phi \theta$ (jealous and interfering; cf. nota 3 ).

${ }^{25}$ Os Trabalhos e os dias, 174-178.

${ }^{26}$ Levando-se em conta, naturalmente, a variação entre a"Epıs da Teogonia e as duas'Epı $\delta \varepsilon s$ dos Trabalhos e os dias, nas quais Hesíodo parece querer dar ao termo a possibilidade de uma acepção positiva. De qualquer modo, a presença do tema na obra do poeta mostra que a tensão promovida pelăE Eıs é uma condição humana. Cf. Havelock, E. The Greek concept of justice. From its shadow in Homer to its substance in Plato. Cambridge (Mass.)/ London: Harvard University Press, 1978, p. 139-149.

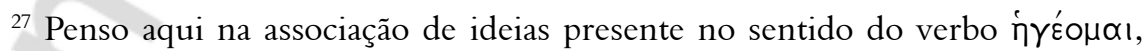

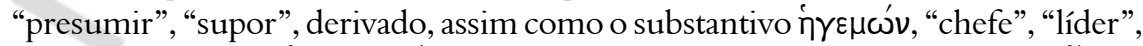

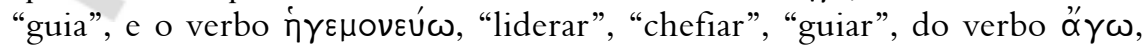
"conduzir", "guiar".
} 
Tirésias no Hades. ${ }^{28} \mathrm{O}$ emprego de émpedos exprime uma associação da vida psíquica à situação da corporeidade do homem no mundo, também manifesta pelo advérbio pedóthen, "desde o chão", derivado, assim como émpedos, de pédon, "chão", "plano", "planície". Lembremo-nos do que diz Atena a Odisseu na passagem citada acima, quando se apresenta a ele em Ítaca e o repreende docemente por seus intermináveis ardis: "Não deixarias,/ mesmo em tua própria terra, de exercitar tuas trapaças/ e o discursos sorrateiros que do fundo < pedóthen > te são tão caros!" ${ }^{29}$

Ainda no campo semântico da firmeza e da estabilidade, notemos, por fim, que o advérbio asphaléos é associado a émpedos para caracterizar o deslocamento estável e seguro da nau dos feácios que leva Odisseu de volta a Ítaca. ${ }^{30} \mathrm{Na}$ passagem do século VI ao V a. C., Parmênides valorizará a firmeza do pensamento, mas com um vocabulário que a associa à fixidez:

Mas olha embora ausentes à mente presentes firmemente; pois não deceparás o que é de aderir ao que é (...). ${ }^{31}$

\footnotetext{
${ }^{28}$ Pátroclo foi ferido por uma flecha de Eurípilo mas "manteve firme sua

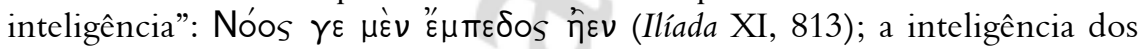
companheiros de Odisseu transformados em porcos: Autò

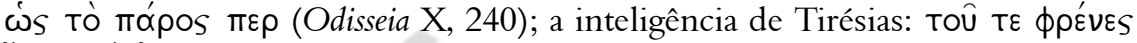

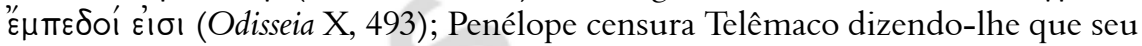

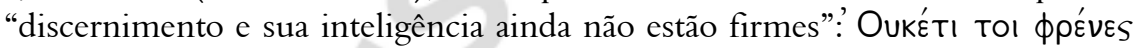

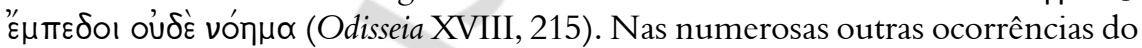
adjetivo, ele qualifica frequentemente a violência ( $\beta^{\prime}$ ín), os membros de um corpo

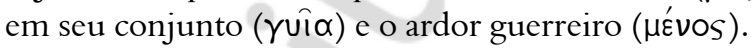

${ }^{29}$ Odisseia XIII, 293-295. Kozlik, H. Le vocabulaire de la force et de la violence dans l' "Iliade". Etude sémantique. Mémoire de maitrise sous la direction de J. Schwartz et L. Christmann. Strasbourg: Université de Strasbourg, 1983, p. 84, observou, precisamente a respeito do adjetivo émpedos, que "uma certa imobilidade corresponde a uma afirmação da força”. E mais adiante, p. 85, acerca do verbo $\mu \varepsilon ́ v \omega$ : "Essa força imóvel é superior à força ativa que quer mostrar Eneias, já que

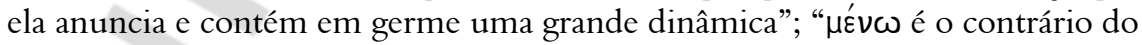
movimento, de uma ação negativa que consistiria em fugir. Exprimindo a força, a raiz $\mu \varepsilon ́ v \varepsilon$ - é frequente como primeiro termo do composto, notadamente na onomástica, ou nos epítetos".

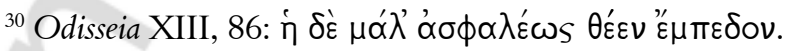

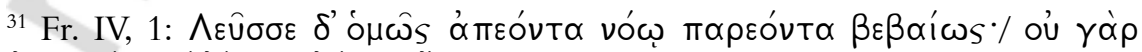

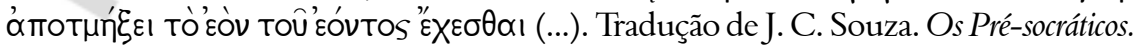
Volume I. São Paulo: Nova Cultural, 1989, p. 88.
} 
Entre a vasta influência da poesia heroica e a crescente afirmação do conhecimento dos pensadores da época arcaica, o "cuidado" se definirá como a tarefa peculiar da sabedoria. As análises de Foucault negligenciam um aspecto da sabedoria que Sócrates não apenas respeitou e valorizou, mas desenvolveu e elevou a um princípio filosófico no sentido mais denso da expressão: a compreensão do destino humano sob a influência de uma divindade anônima, o daímon. A dualidade theós - daímon que, como observei, acompanha a religião grega desde os testemunhos mais antigos, apresenta o divino como uma experiência de desconhecimento da realidade, de encontro com o inominável.

Mais do que uma dualidade, o mais apropriado seria referir-se à experiência expressa por theós - daímon como uma identidade dual, porque ambos os termos se empregam em contextos tão próximos sem deixar de conservar suas enigmáticas especificidades. Na medida em que indica uma divindade anônima, o daímon é antes de mais nada o fruto de uma religião que precisou criar um elemento divino quase impessoal para mergulhar ainda mais fundo na conturbada pessoalidade dos deuses, talvez como nenhuma outra religião conhecida. Os diálogos platônicos são a expressão filosófica mais aguda e mais sofisticada desse princípio.

Ao mesmo tempo em que Platão se insere nessa tradição e compreende o conhecimento como a firmeza com que o sábio se posiciona e caminha na vida, não são poucas as passagens em que ele salienta a incerteza das verdadeiras questões humanas, aquelas em que o nosso destino parece não fazer sentido a não ser como compromisso com o divino. ${ }^{32} \mathrm{O}$ desafio, para Platão, é que não há como se falar do humano sem se pensar no divino. ${ }^{33}$ Para citar uma passagem muito comentada, quando, no livro VI da República, Sócrates e Adimanto tratam

\footnotetext{
${ }^{32}$ A aproximação do divino é o que permite aos homens alçar-se acima da volubilidade dos interesses imediatos, responsável pela degradação moral como, por exemplo, a descrita por Tucídides na época da peste de 430-429 a. C. (História da guerra do Peloponeso II, 53, 1. Thucydidis. Historiae. Volume I. Edição e anotação crítica por H. S. Jones. Complementação do aparato critic por J. E. Powell. Oxford: Oxford University Press, 1902): "Primeiro a doença começou e acabou levando a cidade a mais desregramentos, pois mais facilmente uma pessoa ousava fazer à vontade aquilo que antes escondia, olhando a transformação abrupta daqueles que, felizes, repentinamente morrem, e dos outros que, antes nada possuindo, logo passam a ter o que àqueles pertencia”.

${ }^{33}$ Cf. Burkert, op. cit., p. 282: Als Sokrates die einzigartige innere Erfahrung, die ihn in unvorhersehbarer Weise in den verschiedensten Situationen zwangshaft innehalten, neinsagen und umkehren hieb, in Worte zu fassen suchte, sprach er lieber als von "Göttlichem" von etwas "Daimon-haftem", vom daimónion, das ihm begegne. Dies konnte als Umgang mit Geistern, als geheimer Kult mißdeutet werden; dies hat Sokrates das Leben gekostet.
} 
do modo como as cidades poderão evitar que a filosofia pereça, o primeiro diz: "Com efeito, as grandes coisas são escorregadias e, conforme o dito, as coisas belas são realmente improváveis."

Para avaliar a singularidade dessa afirmação, observemos que essa é a única occorrência do adjetivo episphalés na obra de Platão, termo derivado do verbo sphállo, "fazer escorregar", "abalar". ${ }^{34}$ Lembremonos também do epíteto da Terra na Teogonia de Hesíodo, 117:

\section{Gaî' 'eurústhernos, pánton hédos asphalès aieí, ${ }^{35}$}

A firmeza que caracteriza a inteligência confiável em Homero e o olhar do sábio para Parmênides é, para Platão, justamente o que não se consegue ter ao se tratar das grandes questões.

\section{Para uma conclusão}

A associação entre o cuidado de si e o divino é o tema central do Alcibíades, diálogo tantas vezes desautorizado pelos estudiosos da obra platônica mas que partilha com os demais diálogos alguns dos temas centrais do platonismo. Não poderia propor-me aqui a dirimir as dúvidas relativas à sua autenticidade, limitando-me a apontar a importância do tema do pensamento subreptício, extemporâneo. Platão chamou a isso de daímónion, na concepção de cuidado de si presente nesse e em outros diálogos.

A importância da natureza imprevisível do pensamento, de seu caráter subreptício, está em aceitar que o conhecimento que procuramos implica um engajamento em algo que nos excede, eterno e, portanto, transcendente aos limites da experiência mortal, mas a que podemos aceder provisoriamente em certas concepções não anunciadas pelas premissas da argumentação. É esse engajamento com o divino que deve ser descoberto para qualificar de fato um pensamento, mas não através de algum misticismo, de algum rito de iniciação preestabelecido, passível

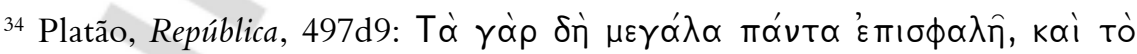

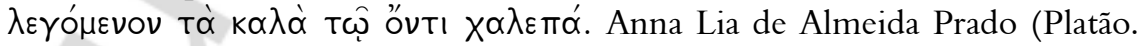
República. Trad. A. L. A. Prado.) traduz o neutro plural ' $\varepsilon \pi ı \phi \alpha \lambda \hat{n}$ nessa passagem por “instáveis”, F. M. Cornford (Plato. The 'Republic' of Plato. Tradução, introdução e notas por F. M. Oxford: Oxford University Press, 1941), por hazardous ("arriscados", "incertos").

${ }^{35}$ Hesíodo, Teogonia, 117: "Terra de amplos seios, de todos sede irresvalável sempre, (...)". Tradução de J. A. A. Torrano.
} 
de ser escrito, por exemplo, ou transmitido entre partidários de um conhecimento secreto, mas sim por nossa confiança em encontrar verdades que venham a aparecer-nos acerca da melhor forma de vida.

No início do diálogo Eutífron, por exemplo, Sócrates conta ao personagem homônimo como lhe foi apresentada a acusação de que corrompe a juventude por um certo Meleto. Eutífron lhe responde:

Compreendo, Sócrates: porque você diz que de vez em quando uma intervenção divina lhe ocorre. Então essa acusação o acusa de ser um inovador acerca das coisas divinas (...). ${ }^{36}$

E na Apologia de Sócrates, defendendo-se dessas acusações, Sócrates dirá aos juízes:

Talvez parecesse estranho que eu, em encontros privados, delibere junto com meus interlocutores e seja muito ativo, já na vida pública não ouso, dirigindo-me à multidão, deliberar com a vossa cidade. $\mathrm{E}$ a causa disso é justamente o que vós me ouvistes dizer muitas vezes, a saber, que me ocorre algo de divino e de repentinamente divino, isso de que Meleto, distorcendo comicamente, também me acusou na acusação. Mas isso começou em minha infância, uma voz ocorrendo-me, a qual, quando ocorre, sempre me impede disso que estou prestes a fazer, nunca me incita avante. É o que me impede de agir na vida pública da cidade. ${ }^{37}$

Em ambas as passagens, presenciamos, pela arte dramática de Platão, o pensamento chegando repentinamente e não podendo ser interrompido; pode, porém, deter-se pela dificuldade de seu próprio movimento. ${ }^{38} \mathrm{~A}$ desatenção de Foucault quanto a esse aspecto do Sócrates platônico é

\footnotetext{
${ }^{36}$ Platão, Eutifron $3 \mathrm{~b}$.

${ }^{37}$ Platão, Apologia de Sócrates 31c-d.

${ }^{38}$ Platão, Protágoras, 314b-c: antes de adentrar a casa de Cálias, Sócrates e Hipócrates detêm-se para concluir a conversa que haviam começado (e cujo assunto não nos

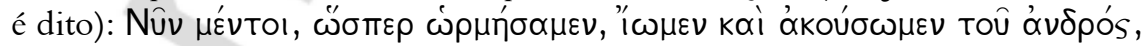

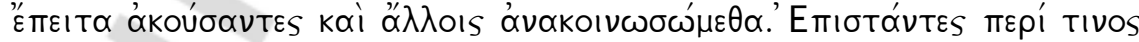

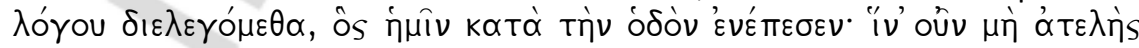

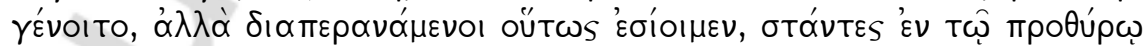

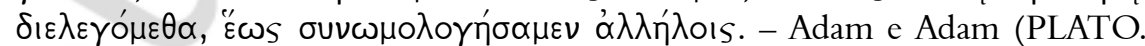
Protagoras. Introdução, notas e apêndices por J. Adam e J. M. Adam. Cambridge: Cambridge University Press, 1893.) lembram que a cena remete a Banquete, 175a, quando Sócrates detém-se no caminho para concluir a reflexão que lhe havia ocorrido ao dirigir-se à casa de Agaton. Para a influência dessa visão na concepção platônica de inspiração poética, veja-se Ion, 533c-534.
} 
comparável com a negligência da importância filosófica do daímon pela crítica platônica moderna e se insere nessa tradição de comentários, ainda que o próprio Foucault não o perceba. ${ }^{39}$

É apenas no curso "O governo de si e dos outros: a coragem da verdade", ministrado dois anos após a "Hermenêutica do sujeito", que o tema do daimónion que acometia Sócrates será abordado, mas de um modo muito tangencial. Nessa ocasião Foucault se concentrará estritamente nos aspectos políticos da recomendação de que Sócrates se abstivesse de participar diretamente nas instituições políticas da cidade. Ao expor sua brilhante concepção de que a parhesía é uma das quatro formas de veridição formuladas na Grécia (junto com o uso da palavra pelo profeta, pelo sábio e pelo professor), Foucault deixou de lado a relação entre o daimónion e a máxima do "conhece-te a ti mesmo", negligenciando que a noção de conhecimento recomendada por esta remete a uma abertura para o inexplicável do divino em que o filósofo se vê despossuído dos recursos da razão. ${ }^{40}$

${ }^{39}$ Cf. Friedländer, P. Platon. I. Band. Seinswahrheit und Lebenswirklichkeit. Berlin: Walter de Gruyter: 1964, p. 34.

${ }^{40}$ Foucault, M. Le courage de la vérité. Le gouvernement de soi et des autres II. Cours au Collège de France 1983-1984. Édition établie, sous la direction de F. Ewald et A. Fontana, par F. Gros. Collection "Les Hautes Études". Paris: Gallimard/ Seuil, 2009. Apesar de anunciadas no ementário que aparece na abertura da $1^{\text {a }}$ hora da aula do dia 15 de fevereiro de 1984 como a alíquota "Le démon de Socrate" (p. 67), as brevíssimas considerações de Foucault sobre o daimónion não o levam a refletir sobre a concepção socrático-platônica de conhecimento como uma abertura para o instante, como proponho aqui. Nessa leitura de Foucault - de resto, totalmente influenciada pela interpretação tradicional da perspectiva platônica do conhecimento - a compreensão do divino como daimónion simplesmente parece não incidir sobre o que seja "pensar" nem, consequentemente, sobre o que seja "cuidar" no âmbito dos diálogos. Sintomaticamente (mas talvez por simples esquecimento ou pela acidentalidade infeliz que afetou a história desses últimos cursos no Collège de France), o anúncio da reflexão sobre o daimónion não será cumprido no corpo do texto. No texto que temos, a reflexão de Foucault não passa da seguinte observação (p. 74): "É preciso não esquecer - nós teremos ocasião de voltar a isso - que todo esse ciclo da morte socrática evoca a pontuação de um certo número de intervenções divinas (Il ne faut pas oublier - on aura à y revenir - que tout ce cycle de la mort socratique évoque la ponctuation d'un certain nombre d'interventions divines.). É triste que não possamos mais lhe perguntar (o que certamente não nos exime de colocar a questão!): se esse daimónion interferiu tão decisivamente na vida de Sócrates (segundo Platão), será que a máxima délfica não exige uma leitura menos positiva da relação socrática com o conhecimento, no sentido de integrar a tragicidade do destino - tão presente nas obras sobre a morte do filósofo - na aventura do pensamento?”. 
A exigência de que eventualmente tomemos decisões sem o amparo de uma argumentação suficiente é a aceitação da precariedade da nossa relação com a verdade. No contexto do platonismo, o "cuidado de si" guarda a abertura para o novo de que se reveste o bem ao olhar parcial, estreito, dos homens. A experiência da errância que define a Odisseia e as aventuras de seu herói filosófico, "que muito errou" (hos mála pollà plánkhthe, v. 2), continua animando a concepção socráticoplatônica de conhecimento. O diálogo encena as forças criativas que atravessam nossa vida efêmera e cotidiana. $\mathrm{O}$ cuidado a que nos convida se tece nas relações entre concidadãos e não poderia limitar-se a um conjunto de preceitos, alheios ao efeito que a vida de cada um tem permanentemente sobre a coletividade. A mudança é inerente ao lógos em que se baseiam as boas relações humanas, aquelas, no entender de Platão, que se atam por um bem comum.

\section{Referências}

BURKERT, W. Griechische Religion der archaischen und klassischen Epoche. Die Religionen der Menschheit, 15. Stuttgart/ Berlin/ Köln/ Mainz: W. Kohlhammer, 1977.

CLAY, J. S. The wrath of Athena. Gods and men in the Odyssey. Lanham/Boulder/ New York/ London: Rowman \& Littlefield, 1997.

DARAKI, M. Le héros à "menos" et le héros "Daimoni Isos". Une polarité homérique. Annali della Scuola Normale Superiore di Pisa. Pisa, vol. X, p. 1-24, 1980.

DETIENNE, M. Les maîtres de vérité dans la Grèce archaïque. Paris: Pocket, 1985.

DODDS, E. R. The Greeks and the irrational. Berkeley/ Los Angeles/ London: University of California Press, 1951.

DOURADO-LOPES, A. O. A força e o antropomorfismo dos deuses gregos. Considerações sobre a religião dos poemas homéricos. Aletria. Revista de Estudos de Literatura. Belo Horizonte, vol. XIX, n. 3, p. 11-27, julho-dezembro de 2009.

FOUCAULT, M. Herméneutique du sujet. Cours au Collège de France 1981-1982. Édition établie, sous la direction de F. Ewald et A. Fontana, par F. Gros. Collection "Les Hautes Études”. Paris: Gallimard/ Seuil, 2001.

. Le courage de la vérité. Le gouvernement de soi et des autres II. Cours au Collège de France 1983-1984. Édition établie, sous la direction de F. Ewald et A. Fontana, par F. Gros. Collection “Les Hautes Études”. Paris: Gallimard/ Seuil, 2009.

FRIEDLÄNDER, P. Platon. I. Band. Seinswahrheit und Lebenswirklichkeit. Berlin: Walter de Gruyter, 1964.

van GRONINGEN, A. Les trois Muses de l'Hélicon. L'Antiquité Classique. Louvain, p. 287-296, 1948. 
HAVELOCK, E. The Greek concept of justice. From its shadow in Homer to its substance in Plato. Cambridge (Mass.)/ London: Harvard University Press, 1978.

HESIOD. Works and days. Edição, introdução e notas por M. L. West. Oxford: Oxford University Press, 1978.

Teogonia. A origem dos deuses. Tradução em versos e introdução por J. A. A.

Torrano. São Paulo: Iluminuras, 1992.

HOMERUS. Homeri opera. Tomus I: Iliadis libros I-XII continens. Tomus II: Iliadis libros XIII-XXIV continens. Edição e anotação crítica por D. Monro e T. Allen. 3. ed. Oxford: Oxford University Press, 1920.

. Homeri opera. Tomus III: Odysseae libros I-XII continens. Tomus IV: Odysseae libros $\overline{X I I I-X X I V . ~ E d i c ̧ a ̃ o ~ e ~ a n o t a c ̧ a ̃ o ~ c r i ́ t i c a ~ p o r ~ T . ~ A l l e n . ~ 3 . ~ e d . ~ O x f o r d: ~ O x f o r d ~ U n i v e r s i t y ~}$ Press, 1969.

KOZLIK, H. Le vocabulaire de la force et de la violence dans l' "Iliade". Étude sémantique. Mémoire de maitrise sous la direction de J. Schwartz et L. Christmann. Strasbourg: Université de Strasbourg, 1983.

KULLMANN, W. Das Wirken der Götter. Untersuchungen zur Frage der Entstehung des homerischen "Götterapparatts". Berlin: Akademie, 1956.

LESKY, A. Göttliche und menschliche Motivation im homerischen Epos. Sitzungsbericht der Heidelberger Akademie der Wissenschaften. Heidelberg: Heidelberger Akademie der Wissenschaften, 1961, p. 5-52.

NILSSON, M. P. Geschichte der griechischen Religion. I. Band: die Religion Griechenlands bis aufdie griechische Weltherrschaft. Munique: C. H. Beck'sche, 1967.

PLATÃO. República. Trad. A. L. A. Prado. São Paulo: Martins Fontes, 2003.

. Protagoras. Introdução, notas e apêndices por J. Adam e J. M. Adam.

Cambridge: Cambridge University Press, 1893.

The 'Republic' of Plato. Tradução, introdução e notas por F. M. Cornford. Oxford: Oxford University Press, 1941.

. Platonis opera. Tomus I. Tetralogias I-II continens. Edição e anotação crítica por E. A. Duke, W. F. Hicken, W. S. M. Nicoll, D. B. Robinson e J. C. G. Strachan. Oxford: Oxford University Press, 1995.

RUTHERFORD, R. B. The philosophy of the "Odyssey". In: de JONG, I. J. F. (Org.). Homer. Critical assessments. Vol.IV: Homer's art. London/New York: Routledge, 1999, p. 271-298.

SEGAL, C. Celui qui a tout vu. Europe. Paris, vol. QCCCLXV, p. 68-101, 2001.

SHIPP, G. P. Studies in the language of Homer. Cambridge: University Press, (1953) 1972. SOUZA, J. C. Os Pré-socráticos. Volume I. São Paulo: Nova Cultural, 1989.

THUCYDIDIS. Historiae. Edição e anotação crítica por H. S. Jones. Complementação do aparato crítico por J. E. Powell. Oxford: Oxford University Press, 1902. 